\title{
Immunoglobulin M Antibodies Present in the Acute Phase of Kawasaki Syndrome Lyse Cultured Vascular Endothelial Cells Stimulated by Gamma Interferon
}

Donald Y. M. Leung, Tucker Collins, Lynne A. Lapierre, Raif S. Geha, and Jordan S. Pober

Departments of Pediatrics and Pathology, Harvard Medical School; Division of Allergy, The Children's Hospital; and Department of Pathology, Brigham and Women's Hospital, Boston, Massachusetts 02115

\begin{abstract}
Kawasaki syndrome (KS) is characterized by diffuse vasculitis and marked $T$ cell and $B$ cell activation. In this study, sera from 16 patients with acute KS, 15 patients in the convalescent phase of KS, and 19 age-matched controls were assessed for complement dependent cytotoxic activity against ${ }^{111}$ In-labeled human umbilical vein endothelial (HUVE) cells. Neither sera from patients with KS nor sera from controls had cytotoxic effects on HUVE cells cultivated under standard conditions. Since activated $T$ cells such as those present in acute KS secrete gamma interferon ( $\gamma$-IFN), we also examined the effects of sera from acute KS on HUVE cells preincubated with $\boldsymbol{\gamma}$-IFN. We report here that immunoglobulin $M$ (IgM) antibodies in sera from patients with acute KS cause significant $(P<0.01)$ killing of $\gamma$-IFNtreated HUVE cells. Pretreatment with interleukin 2, $\gamma$-IFN, or $\boldsymbol{\beta}$-IFN failed to render HUVE susceptible to lysis with acute KS sera. The observed effects were not mediated via immune complexes. The cytotoxic antibodies in acute KS seem to be directed against inducible monomorphic antigenic determinants present on $\boldsymbol{\gamma}$-IFN-treated HUVE cells but not on control or $\boldsymbol{\gamma}$ IFN treated autologous human dermal fibroblasts (HDF). Similarly, acute KS sera also induced lysis of $\boldsymbol{\gamma}$-IFN-treated human saphenous vein endothelial (HSVE) cells but not $\boldsymbol{\gamma}$-IFN treated human saphenous vein smooth muscle (HSVSM) cells. Since $\gamma$-IFN induces the same level of class I and class II major histocompatibility complex (MHC) antigen expression on HDF, HUVE, HSVE, and HSVSM cells, our results suggest that the anti-endothelial cell antibodies in acute KS are directed to $\boldsymbol{\gamma}$ IFN-inducible molecules other than MHC determinants. These observations are further substantiated by the failure of human $B$ cells or monocytes to absorb the anti-endothelial cell activity. Since most vasculitides, including acute KS, are characterized both by marked immune activation and the secretion of lymphokines, antibodies directed to $\boldsymbol{\gamma}$-IFN-inducible endothelial cell antigens may represent a general mechanism for vascular injury.
\end{abstract}

\section{Introduction}

Kawasaki syndrome (KS) ${ }^{1}$ is an acute febrile illness of early childhood characterized by diffuse mucosal inflammation, in-

Address correspondence to Dr. Leung.

Received for publication 25 September 1985 and in revised form 23 December 1985.

1. Abbreviations used in this paper: HDF, human dermal fibroblasts; HSVE, human saphenous vein endothelial cells; HSVSM, human sa-

J. Clin. Invest.

(C) The American Society for Clinical Investigation, Inc.

0021-9738/86/05/1428/08 \$1.00

Volume 77, May 1986, 1428-1435 durative edema of the hands and feet, polymorphous skin rash, and nonsuppurative cervical lymphadenopathy $(1,2)$. This disease has aroused much interest because it has been associated with sudden death due to coronary arteritis accompanied by coronary aneurysms and thrombotic occlusion $(3,4)$. The histopathologic findings in $\mathrm{KS}$ indicate a panvasculitis with endothelial necrosis, immunoglobulin (Ig) deposition, and mononuclear cell infiltration into small and medium-sized blood vessels $(5,6)$. Indeed, although much attention has been focused on the occurrence of coronary arteritis in this disease, aneurysms of other medium-sized arteries (e.g., renal, splenic, pulmonary) also occur $(7,8)$. In addition, venulitis is a prominent finding in autopsy studies of acute KS (8).

Despite the increasing incidence of $\mathrm{KS}(9)$, very little is known about the etiology of this disease. Several previous observations, however, suggest that immunoregulatory abnormalities contribute to the pathogenesis of this disease. First, there is an increased incidence of HLA-Bw22 in Japanese children with KS (10) and of HLA-Bw51 in Caucasian children with KS (11). Second, the acute phase of $\mathrm{KS}$ is characterized by a deficiency of circulating $\mathrm{T} 8+$ suppressor/cytotoxic $\mathrm{T}$ cells, increased numbers of $\mathrm{T} 4+$ activated helper $T$ cells bearing the HLA-DR surface antigen, and a 10- to 1,000-fold increase in the number of activated $B$ cells spontaneously secreting $\operatorname{IgG}$ and $\operatorname{IgM}(12,13)$. With few exceptions, each of these three immunoregulatory abnormalities resolves during the convalescence phase of KS. Third, circulating immune complexes have been reported in some patients, with KS most frequently reported 2-4 wk after the onset of their illness $(14,15)$.

In this study, we investigated the possibility that antibodies to vascular endothelial cells could play a role in the pathogenesis of KS. Initial studies indicated that neither sera from patients with KS nor sera from age-matched controls had cytotoxic effects on cultured human umbilical vein endothelial (HUVE) cells. Since activated helper T cells such as those present in KS secrete gamma interferon ( $\gamma$-IFN), a potent inducer of major histocompatibility complex (MHC) class I and class II antigens (16) as well as several other proteins (for example, references 16-18), we also examined the effects of sera from acute KS on HUVE cells preincubated with $\gamma$-IFN. We report that IgM antibodies in sera from patients with acute KS cause complement-mediated killing of $\gamma$-IFN-treated endothelial cells. The cytotoxic antibodies in acute $\mathrm{KS}$ appear to be directed against inducible antigenic determinants present on $\gamma$-IFN-treated human vascular endothelial cells but not on control or $\gamma$-IFN-treated autologous

phenous vein smooth muscle; HUVE, human umbilical vein endothelial cells; $\gamma$-IFN, gamma interferon; I.C., immune complexes; IgG, M, immunoglobulin $\mathrm{G}$ and $\mathrm{M}$, respectively; IL-2, interleukin 2; KS, Kawasaki syndrome; MAb, monoclonal antibody; MHC, major histocompatibility complex; SLE, systemic lupus erythematosus; SR, specific release. 
human dermal fibroblasts (HDF) nor on human vascular smooth muscle cells.

\section{Methods}

Cells. HUVE cells were isolated by collagenase treatment of single or pooled (two to six donors) normal term umbilical cord segments and were cultured in Medium 199 containing 20\% (vol/vol) heat-inactivated fetal bovine serum supplemented with $125 \mathrm{U} / \mathrm{ml}$ penicillin, $125 \mu \mathrm{g} / \mathrm{ml}$ streptomycin, and $2 \mathrm{mM}$ L-glutamine (M199-FBS, all components from M. A. Bioproducts, Walkersville, MD) as described elsewhere (19). HUVE cultures were serially passaged as described by Thornton et al. (20) using endothelial cell growth supplement $(50 \mu \mathrm{g} / \mathrm{ml}$, kindly provided by Dr. Thomas Maciag, Revlon Biotechnology Research Center, Rockville, MD) and porcine heparin $(100 \mu \mathrm{g} / \mathrm{ml}$; Sigma Chemical Co., St. Louis, MO) on $0.1 \%$ gelatin-coated (Difco Laboratories, Inc., Detroit, MI) plastic. Both the primary cultures and the serially subcultured strains formed a "cobblestone"-appearing monolayer at confluence and uniformly stained positive for Factor VIII antigen (21). For each cytotoxicity experiment, $\sim 1 \times 10^{4}$ cells were plated into 96 flat bottom microtiter wells (Costar, Cambridge, MA) (day 0) and refed (day 1) with or without $\gamma$-IFN (200 $\mathrm{U} / \mathrm{ml}$, see below). A uniform-appearing confluent monolayer was established in 3-4 d.

HDF strains were cultured using previously reported methods (22, 23) and multiply passaged in medium 199 supplemented with $15 \%$ fetal bovine serum, antibiotics, and L-glutamine. For each experiment, $\sim 1 \times 10^{4}$ fibroblasts, at passages 5 to 15 , were plated into Costar 96 flat-bottomed microtiter wells (day 0 ) and were refed (day 1) with or without added $\gamma$-IFN ( $200 \mathrm{U} / \mathrm{ml}$, see below). Cultures normally reached visual confluence by day 3-4. Cultured human saphenous vein endothelial (HSVE) cells and human saphenous vein smooth muscle (HSVSM) cells were obtained as generous gifts from Dr. Peter Libby (Tufts University School of Medicine, Boston, MA). These cells were subsequently cultured and treated under the same culture conditions as the passaged HUVE and $\mathrm{HDF}$, respectively.

Treatment of HUVE and HDF cultures with $\gamma-I F N$ and other mediators. HUVE and HDF cultures were routinely treated on day 1 (subconfluent) with recombinant $\gamma$-IFN as $0.1 \%$ medium conditioned by a transfected Chinese hamster ovary fibroblast line (a final concentration of $200 \mathrm{U} / \mathrm{ml}$ interferon activity assayed on FS4 cells, ref. 23; a generous gift of Dr. Walter Fiers, State University of Ghent, Ghent, Belgium). Replicate cultures were treated with control medium conditioned by a cell line transfected without the $\gamma$-IFN genes (24). These conditioned media at the concentrations used in these experiments did not induce cytopathic effects in either HUVE or HDF cells. As previously demonstrated by radioimmunoassay and fluorescence flow cytometry (22), control-treated cultures of both cell types express HLA-A,B antigens but not HLA-DR or DQ antigens; after $\gamma$-IFN treatment, both cell types uniformly increase expression of HLA-A,B and uniformly express HLADR and DQ antigens. Expression of HLA-DR by HUVE and HDF cells derived from the same donor is quantitatively equivalent (Guinan, E. C., and J. S. Pober, unpublished observations). In some experiments, the cultures were treated for $4 \mathrm{~d}$ with other mediators such as recombinant interleukin 2 (IL-2; $100 \mathrm{U} / \mathrm{ml}$, Biogen, Cambridge, MA), recombinant human fibroblast interferon (expressed in Escherichia coli and purified to homogeneity at $1,000 \mathrm{U} / \mathrm{ml}$, a generous gift of Dr. Walter Fiers) and recombinant human leukocyte interferon $(1,000 \mathrm{U} / \mathrm{ml}$, Amgen, Thousand Oaks, CA). Each of these mediator preparations was active in modulating endothelial cell HLA-A,B surface antigen expression in appropriate assays (16), except IL-2, which was active in T cell growth assays (25).

Sera. A total of 31 samples of sera were obtained from 18 children with KS ( 10 males, 8 females; mean age $=2.5 \mathrm{yr}$, age range, 7 mo to 8 yr): 16 samples were obtained during the acute phase of KS, i.e., within 3 wk of the onset of fever; and 15 samples were obtained during the convalescent phase of KS (2-4 mo after resolution of acute symptoms). 13 patients were studied during both the acute and convalescent phase of their illness. The diagnostic criteria for KS was fever of unknown etiology lasting 5 or more $d$ and at least four of the five following symptoms and signs: $(a)$ bilateral conjunctivitis; $(b)$ changes of lips and oropharynx (diffuse reddening of oropharyngeal mucosa; dryness, fissuring and/or reddness of lips; and protuberance of tongue papillae, i.e., "strawberry tongue"); ( $c$ ) changes in peripheral extremities (reddening of palms and sole; indurative edema; and periungal desquamation); $(d)$ nonpurulent cervical lymphadenopathy of $1.5 \mathrm{~cm}$ or more in diameter; and (e) polymorphous exanthem of trunks, without vesicles or crusts. Patients were evaluated for coronary artery aneurysms by two-dimensional echocardiography performed in the Department of Cardiology at Children's Hospital, Boston, MA. Patients suspected of developing coronary artery aneurysms subsequently underwent selective coronary artery angiography. 3 of the 16 acute KS sera were obtained from patients whose course was complicated by the development of coronary artery aneurysms, confirmed by angiography.

Sera were also obtained from 19 age-matched afebrile controls (11 males, 8 females; mean age, $2.7 \mathrm{yr}$, age range, 6 mo to $9 \mathrm{yr}$ ): 13 samples were obtained during evaluations for suspected allergic rhinitis in Allergy Clinic at Children's Hospital, and six samples were obtained during cardiac catheterization for evaluation of noninflammatory congenital heart disease.

In some experiments, sera from patients with acute $\mathrm{KS}$ were subjected to ultracentrifugation at $100,000 \mathrm{~g}$ for $1 \mathrm{~h}$ in an Airfuge (Beckman Instruments, Inc., Fullerton, CA) to remove immune complexes from the sera. In addition, several control sera were heat-treated at $63^{\circ} \mathrm{C}$ for $1 \mathrm{~h}$ to form immune complexes. The concentration of immune complexes formed by heat treatment was quantitated by the Clq binding assay (courtesy of Dr. P. Schur, Brigham and Women's Hospital, Boston, MA).

Informed consent was obtained from each patient and/or their parents before the study.

Serum adsorption studies. In selected experiments, acute KS sera were adsorbed with a variety of cell types to determine whether the target endothelial cell antigen is found on other cells. Each 0.6 cubic centimeter of acute KS sera (diluted 1:2.5) was incubated with either $1.5 \times 10^{6}$ HUVE or $\gamma$-IFN-treated HUVE, $2 \times 10^{6}$ adherent monocytes, T cells, or $B$ cells, or an equal volume of packed red cells.

Mononuclear cells were separated from erythrocytes by Ficoll density gradient centrifugation of heparinized human blood as previously described (13). Suspensions of peripheral blood mononuclear cells were depleted of adherent cells by allowing them to incubate for $1 \mathrm{~h}$ at $37^{\circ} \mathrm{C}$ in plastic petri dishes $\left(5 \times 10^{6} \mathrm{cells} / \mathrm{ml}\right)$. The nonadherent cells were further fractionated into $T$ cells and $B$ cells by double rosetting with sheep red cells pretreated with neuraminidase (13). Adherent monocytes were removed with a rubber policeman after adding ice-cold phosphatebuffered saline (PBS) to the plastic petri dishes. Untreated and $\gamma$-IFNtreated HUVE were recovered from Costar 6 plates with 5 mM EDTA $1 \%$ bovine serum albumin in PBS for $30 \mathrm{~min}$ at $37^{\circ} \mathrm{C}$.

Separation of serum IgG and IgM. Monospecific affinity-purified anti-human IgG and anti-human IgM antibody was purchased from Tago, Inc. (Burlingame, CA). These antisera were then coupled to CNBractivated Sepharose 4B as outlined by the manufacturer (Pharmacia Fine Chemicals, Piscataway, NJ). To separate serum IgG and IgM, acute KS sera were incubated with Sepharose 4B coupled with the appropriate antiserum for $2 \mathrm{~h}$ at $22^{\circ} \mathrm{C}$ on a rotator. The effluent (unbound material) from each suspension was then collected, the beads were washed extensively with ice-cold PBS, and the respective immunoglobulin isotype was eluted with $3 \mathrm{M}$ sodium thiocyanate at $4^{\circ} \mathrm{C}$. The eluates and effluents were immediately dialyzed against RPMI culture medium, adjusted to their original serum volumes, and stored at $-80^{\circ} \mathrm{C}$ until tested.

Monoclonal antibodies. Two monoclonal antibodies reacting with MHC antigens were used: $\mathrm{W} 6 / 32\left(\mathrm{IgG}_{2 \mathrm{a}}\right.$, directed against an HLA-A,B

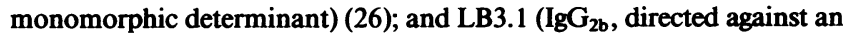
HLA-DR monomorphic determinant) (27), both gifts of Dr. Jack Strominger, Dana Farber Cancer Institute, Boston, MA. A nonbinding mouse monoclonal antibody, $\mathrm{UPC} 10\left(\mathrm{IgG}_{2 a}\right.$, mouse myeloma protein, Walgene $R$ and D Laboratories, Inc., Arcadia, CA) was used as a control for nonspecific binding.

Detection of cytotoxic antibodies. An ${ }^{111}$ In release assay was used to 
detect cytotoxic anti-endothelial (HUVE or HSVE) cell, anti-smooth muscle (HSVSM) cell, or anti-fibroblast (HDF) antibodies in KS patient or control sera. Cells in monolayer cultures in Costar 96-well microtiter plates were control-treated or treated with recombinant $\gamma$-IFN for 3-5 d before assay. Confluent monolayers labeled with "'In as previously described (27). For complement-dependent lysis, the wells were incubated with $100 \mu$ l of human serum diluted 1:2.5 in Hanks' balanced salt solution (HBSS) or with monoclonal antibodies at a final concentration of $1 / 100$ ascites fluid by volume. After $30 \mathrm{~min}$ at $37^{\circ} \mathrm{C}$, the monolayers were washed twice with Tyrode's-albumin solution, before addition of 0.20 $\mathrm{ml}$ of $2.0 \%$ Nonidet P-40 (NP-40, Sigma Chemical Co.) or of baby rabbit complement (Pel-Freeze Biologicals, Rogers, AR) diluted 1:1 with Tyrode's. After $60 \mathrm{~min}$ at $37^{\circ} \mathrm{C}$ the microtiter plates were centrifuged briefly, and $0.10 \mathrm{ml}$ of supernatant was removed, and released "'In was measured using a Beckman model gamma 8000 (Beckman Instruments, Inc.). Percent specific release (SR) was calculated as follows: (cpm experimental - cpm spontaneous)/(cpm total - cpm spontaneous).

To insure interexperimental reproducibility in the measurement of ${ }^{111}$ In release from HUVE, HSVE, HSVSM cells, or HDF in response to antibody and complement, we utilized murine monoclonal antibody (MAb) reactive to human MHC determinants in each experiment. The results in Table I reconfirm previous observations (28) which demonstrate that control-treated HUVE cells and HDF are lysed by MAb reactive with HLA-A,B but not HLA-DR antigens; however, after $\gamma$-IFN treatment both HLA-A,B and HLA-DR MAb are cytolytic. Similar results were obtained with HSVE and HSVSM. After cytolysis, the entire target cell population shows morphologically detectable damage, although only 45 to $65 \%$ ( $n=35$ experiments) of the total radioactivity releasable with $2 \% \mathrm{NP}-40$ is released by treatment with MAb and complement. In the serum antibody cytotoxicity experiments, treatment with Class I MAb (W6/32) plus complement was used to establish maximal radioactivity that could be released. Also, Class II MAb (LB3.1) plus complement was used in each experiment to confirm that $\gamma$-IFN treatment had been effective.

Statistics. Comparison between the cytotoxic effects of patient and control sera were carried out using the nonparametric Wilcoxon ranksum test. The results are expressed as the mean \pm 1 SD.

\section{Results}

Cytolysis of vascular endothelium treated with $\gamma-I F N$ and other mediators by sera from patients with acute $K S$. Sera from patients

Table I. Cytolysis of HUVE Cells and HDF by Monoclonal Antibodies*

\begin{tabular}{lllcc}
\hline \multirow{2}{*}{ Cells } & & & \multicolumn{2}{c}{ Percent specific release } \\
\cline { 4 - 5 } HUVE & Treatment & specificity & $(-) \gamma$-IFN & $(+) \gamma$-IFN \\
& $2 \%$ NP-40 & Detergent & 100.0 & 100.0 \\
& W6/32 & HLA-A,B & 48.6 & 46.3 \\
& LB3.1 & HLA-DR & 0.8 & 45.5 \\
& UPC10 & Control & 0.7 & 0.9 \\
HDF & 2\% NP-40 & Detergent & 100.0 & 100.0 \\
& W6/32 & HLA-A,B & 45.6 & 49.8 \\
& LB3.1 & HLA-DR & 1.2 & 48.5 \\
& UPC10 & Control & 0.9 & 1.0 \\
\hline
\end{tabular}

\footnotetext{
* Confluent primary HUVE or passaged HDF monolayers grown in the presence or absence of $\gamma$-IFN were labeled with ${ }^{111}$ In and treated with MAb and complement as described in Methods. In this experiment, $100 \%$ specific release was defined as ${ }^{11}$ In releasable with detergent $\left(\sim 100 \times 10^{3} \mathrm{cpm}\right.$ for HUVE cells and $120 \times 10^{3}$ for HDF); control MAb and complement released $<2 \times 10^{3} \mathrm{cpm}$. Data were calculated as the means of triplicate determinations; SD was $<10 \%$.
}

in the acute and convalescent phase of $\mathrm{KS}$ as well as sera from age-matched controls were assayed for the presence of anti-endothelial cell antibodies. Confluent monolayers of ${ }^{111}$ In-labeled primary HUVE cultures, pretreated either with control supernatants or $\gamma$-IFN, were incubated with patient sera or control sera followed by complement.

Sera from 16 patients in the acute phase of KS, 15 patients in the convalescent phase of KS, and 19 age-matched controls failed to cause any significant ${ }^{111}$ In release $(P>0.4)$ from untreated HUVE cultures (Fig. $1 A$ ). In contrast, sera obtained from the same group of patients with acute $\mathrm{KS}$ resulted in significantly higher ${ }^{111}$ In release $(30.3 \pm 16.0 ; P<0.01)$ from HUVE preincubated with $\gamma$-IFN than did sera from age-matched controls $\left(3.4 \pm 4.2 \%{ }^{111}\right.$ In release) as calculated by the Wilcoxon ranksum test. 13 of the 16 acute KS sera caused ${ }^{111}$ In release that was $>2$ SD above the mean value (i.e., $>11.8 \%$ ) obtained using control sera (Fig. $1 \mathrm{~B}$ ). Only 3 of the 15 sera obtained from the convalescent phase of $\mathrm{KS}$ caused ${ }^{111}$ In release greater than the normal range. However, the mean percent ${ }^{111}$ In release caused by convalescent $\mathrm{KS}$ sera $(5.5 \pm 8.8)$ was not significantly different $(P>0.1)$ than that obtained with normal sera and was significantly $(P<0.01)$ less than that caused by acute KS sera.

To determine whether other mediators could also induce HUVE cells to express a target antigen recognizable by acute KS sera, we pretreated HUVE cultures with IL-2, $\alpha$-IFN, and beta interferon ( $\beta$-IFN). No cytotoxic activity was directed to HUVE incubated for $4 \mathrm{~d}$ with these latter mediators (results not shown).

The cytotoxicity to $\gamma$-IFN-treated HUVE cells observed in any individual sera was a reproducible finding. As an example, one serum sample from a patient with acute $\mathrm{KS}$ was studied over a 1-yr period on nine separate preparations of primary HUVE cultures and had a mean cytotoxicity of $35.6 \pm 7.9 \%$ (range, 27.8 to 42.1 ). Sera from seven patients with acute KS,

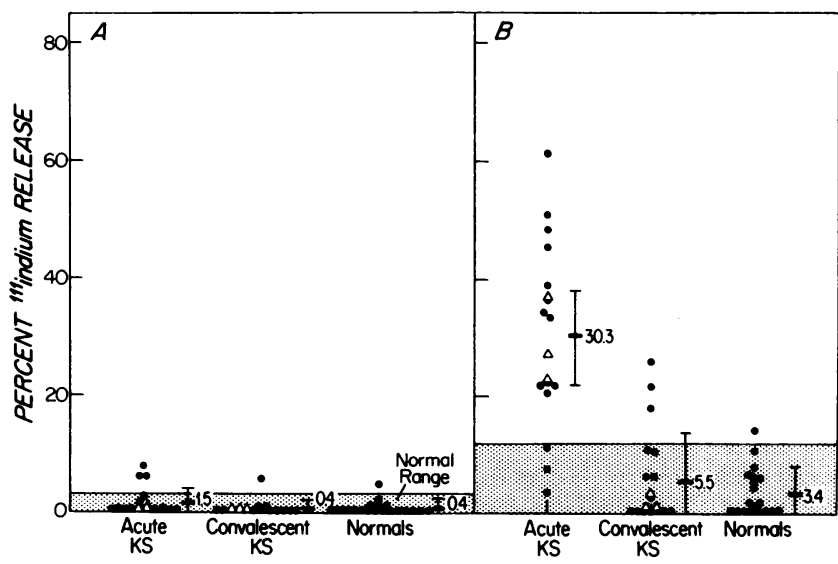

Figure 1. Cytotoxic effects of acute KS sera on cultured endothelial cells. Untreated $(A)$ or $\gamma$-IFN-treated $(B){ }^{111}$ In-labeled HUVE cells in primary culture were sequentially incubated with sera from patients with acute KS, convalescent KS, or normal controls and 1:1 dilution of rabbit serum. The percent specific ${ }^{111}$ In release was determined. The mean \pm 1 SD for each group is shown. Each dot $(\bullet)$ is the mean result of an individual serum performed in triplicate. For sera tested on more than one occasion, the mean value for percent ${ }^{111}$ In release obtained from these multiple determinations is shown. Each triangle $(\Delta)$ is the result obtained using a serum from a patient with coronary artery aneurysms. 
three patients with convalescent $\mathrm{KS}$, and three age-matched controls were studied on more than one occasion. The values reported for these patients in Fig. 1 represent the mean value for percent ${ }^{111}$ In release obtained from these multiple determinations. Whereas in all experiments reported in Fig. 1 a serum dilution of 1:2.5 was used, most sera from patients with acute KS exhibited significant cytotoxicity to $\gamma$-IFN-treated HUVE cells at dilutions of $1: 5$ and $1: 10$, whereas sera from age-matched controls failed to show significant cytotoxicity at any dilution.

3 of the 16 acute KS sera were derived from patients who developed coronary artery aneurysms. The percent specific ${ }^{111}$ In release by these sera $(36.8 \%, 26.1 \%, 25.8 \%)$ were within the mean \pm 1 SD for sera from the acute KS group (Fig. 1). Thus, sera from acute KS patients who developed coronary artery aneurysms did not exhibit higher levels of anti-endothelial cell activity than patients with an uncomplicated course of KS.

Complement dependence of serum-mediated cytotoxicity in $K S$. Sera from patients with acute $\mathrm{KS}$ were further studied to determine whether their cytotoxic effects on $\gamma$-IFN treated HUVE cells were indeed complement-dependent. In these experiments, ${ }^{111}$ In-labeled $\gamma$-IFN-treated passaged HUVE cultures were initially incubated with sera from patients with acute KS. Subsequently, fresh rabbit serum or heat treated $\left(56^{\circ} \mathrm{C}\right.$ for $\left.1 \mathrm{~h}\right)$ rabbit serum was added to the cultures and the culture supernatants were assessed for release of ${ }^{111}$ In after incubation at $37^{\circ} \mathrm{C}$ for $1 \mathrm{~h}$. As shown in Table II, ${ }^{111}$ In-release was observed only when fresh rabbit serum but not after heat inactivated rabbit serum was added to $\gamma$-IFN-treated HUVE cultures preincubated with KS sera.

Failure of immune complexes (I.C.) to account for cytotoxic effects of KS sera against HUVE. Since circulating I.C. have been reported in patients with acute $K S$, we investigated the possibility that the observed complement-dependent cytotoxic effects of acute KS sera were being mediated via I.C. Two approaches were used to explore this possibility: $(a)$ sera from acute KS were ultracentrifuged at $100,000 \mathrm{~g}$ for $1 \mathrm{~h}$ to sediment I.C., and the $100,000 \mathrm{~g}$ serum supernatants were examined for their capacity to lyse $\gamma$-IFN treated HUVE cultures; and $(b)$ normal sera were heat-treated at $63^{\circ} \mathrm{C}$ for $1 \mathrm{~h}$ to form I.C. and were assessed for complement-dependent endothelial cell cytotoxicity.

The data in Table III indicate that sera from acute $\mathrm{KS}$ patients subjected to centrifugation at $100,000 \mathrm{~g}$ maintain the same level

Table II. Cytotoxic Effects of Kawasaki Sera on $\gamma$-IFN-treated HUVE Cells are Complement Dependent

\begin{tabular}{lll}
\hline & \multicolumn{2}{l}{ Percent specific "'In release in the presence of: } \\
\cline { 2 - 3 } Acute KS serum donor & Rabbit serum & Heat-treated rabbit serum \\
\hline 1 & 32.7 & 0 \\
2 & 33.1 & 0 \\
3 & 22.0 & 0
\end{tabular}

\footnotetext{
"11'In-labeled $\gamma$-IFN treated HUVE cells were incubated initially with sera from 3 patients with acute KS, washed three times followed by the addition of untreated rabbit serum (RS) or heat-treated $\left(56^{\circ} \mathrm{C}\right.$ for $1 \mathrm{~h}) \mathrm{RS}$. KS donors 1 and 2 were tested on primary cultures of HUVE cells, whereas donor 3 was tested on multiply passaged (fifth passage) HUVE culture. Data were calculated from the means of triplicate determinations; SD, $<10 \%$.
}

Table III. Cytotoxic Effect of Acute Kawasaki Sera (KS) is Not Mediated Through Immune Complexes

\begin{tabular}{llll}
\hline & & \multicolumn{2}{l}{$\begin{array}{l}\text { Percent specific "'indium } \\
\text { release }\end{array}$} \\
\cline { 3 - 4 } Serum & Treatment* $^{*}$ & $(-) \gamma$-IFN & $(+) \gamma$-IFN \\
\hline \multirow{2}{*}{ KS I } & Untreated & 0 & 42.2 \\
& $100,000 g$ centrifugation & 0 & 41.4 \\
KS II & Untreated & 0 & 62.8 \\
& $100,000 g$ centrifugation & 0 & 59.1 \\
Normal I & Untreated & 0 & 0 \\
& Heat-treated & 0 & 0 \\
Normal II & Untreated & 0 & 0 \\
& Heat-treated & 0 & 0 \\
& & & \\
\hline
\end{tabular}

\begin{abstract}
* Sera from two patients with acute KS were centrifuged at $100,000 \mathrm{~g}$ for $1 \mathrm{~h}$ in a Beckman Airfuge (Beckman Instruments, Inc.) and the serum supernatants were compared with untreated sera for their ability to lyse ${ }^{111}$ In-labeled $\gamma$-IFN treated or untreated passaged HUVE cells. Sera from two normal donors both containing $<20 \mathrm{ng}$ IgG-I.C./ $\mathrm{ml}$ were incubated at $63^{\circ} \mathrm{C}$ for $1 \mathrm{~h}$ to form immune complexes and were compared with untreated sera for their ability to lyse $\gamma$-IFN treated or control treated passaged HUVE cells. After heat treatment, normal sera I contained $2,300 \mathrm{ng} / \mathrm{ml}$ of IgG-I.C. and normal sera II contained $1,900 \mathrm{ng} / \mathrm{ml}$ of IgG-I.C. as measured by the Clq binding assay. Data were calculated from means of triplicate determinations; $\mathrm{SD},<10 \%$.
\end{abstract}

of anti-endothelial cytotoxicity activity as untreated sera. These results are consistent with our unpublished observations that 10 of 10 sera from patients with acute KS used in this study failed to give detectable levels of I.C. as measured by Raji cell assay or Clq binding assay (data not shown). Furthermore, the formation of I.C. in normal sera by heat treatment (quantitated by Clq binding, courtesy of Dr. P. Schur [Brigham and Women's Hospital, Boston] as described in the footnote to Table III) was not associated with any detectable increase in endothelial cell cytotoxic activity (Table III).

Immunoglobulin isotype of anti-endothelial cell antibodies in acute $K S$. The immunoglobulin class of cytotoxic anti-endothelial cell antibodies in acute $\mathrm{KS}$ was determined by passing serum from patients with acute KS through anti-human IgMand anti-human IgG-conjugated Sepharose 4B columns. Both the effluent and eluate fractions of each column were examined for complement-dependent cytotoxic effects on $\gamma$-IFN-treated passaged HUVE cultures as described above. Table IV shows the results of three acute KS sera before and after absorption with anti-immunoglobulin-conjugated Sepharose 4B. When acute KS sera was absorbed with anti-human IgM Sepharose, the effluent fraction did not contain any cytotoxic anti-endothelial cell activity. However, when acute KS sera was passed through anti-human IgG-conjugated columns, the effluent fraction contained the same level of cytotoxic anti-endothelial cell activity as untreated sera. Thus, the cytotoxic anti-endothelial cell activity seemed to reside in the IgM fraction. These results were further substantiated by the observation that the cytotoxic anti-endothelial cell activity could be eluted from anti-IgM but not the anti-IgG Sepharose (Table IV).

Antigens involved in the cytolysis of $\gamma$-IFN-treated HUVE cells by KS sera are monomorphic. To obtain sufficient numbers 
Table IV. Cytotoxic Effects of Acute Kawasaki Sera on $\gamma$-IFN HUVE Cells is Associated with IgM Fraction

\begin{tabular}{llll}
\hline & \multicolumn{2}{c}{ Percent specific ${ }^{~}{ }^{\prime}$ indium release* $^{*}$} & \\
\cline { 2 - 4 } Serum absorption & Experiment 1 & Experiment 2 & Experiment 3 \\
\hline Unabsorbed & 42.2 & 62.8 & 50.8 \\
$\begin{array}{l}\text { Anti-IgG Sepharose } \\
\quad \text { Effluent }\end{array}$ & 44.0 & 59.1 & 51.1 \\
$\quad$ Eluate & 0 & 0 & 0 \\
$\begin{array}{l}\text { Anti-IgM Sepharose } \\
\text { Effluent }\end{array}$ & 0 & 0.6 & 0 \\
$\quad$ Eluate & 40.5 & 67.8 & 51.5 \\
\hline
\end{tabular}

* Sera from three patients with acute KS were fractionated by absorption over anti-human IgG or anti-human Sepharose. The effluent and eluate fractions of these columns were added to "II In-labeled $\gamma$-IFN-labeled passaged HUVE cultures and ${ }^{11}$ In release was measured after treatment with rabbit complement as described in Methods. Data were calculated from mean of triplicate determinations; SD, $<10 \%$.

of primary HUVE cells for culture, the HUVE cells used in the initial experiments (Fig. 1) were derived from a pool (two to six donors) of umbilical cord segments. Subsequently, we found that HUVE cells serially passaged up to 15 subcultures showed similar uptake of ${ }^{111}$ In and release with antibody plus complement as HUVE cells in primary culture. Thus, technical advances in HUVE cell culture (20) enabled us to study cells from single individuals. Therefore, we wished to exclude the possibility that the cytotoxic anti-endothelial cell antibodies being detected in acute KS were directed to polymorphic determinants, i.e., antigens present on some but not all HUVE cells. In Table V, we determined the cytotoxic activity of five acute KS sera on three $\gamma$-IFN-treated passaged HUVE cell strains each derived from separate individual donors. The data indicate that acute $\mathrm{KS}$ sera caused cytolysis of all three HUVE cell strains. Thus, it would appear that cytotoxic antibodies in acute KS recognize monomorphic determinants on HUVE cells.

Antibodies in acute KS lyse $\gamma-I F N$-treated HUVE cells but not $\gamma$-IFN-treated HDF. The target specificity of cytotoxic antiendothelial cell antibodies in acute $\mathrm{KS}$ was further examined by assessing the ability of sera from patients with acute KS to lyse

Table V. Cytotoxic Effects of Acute KS Sera on $\gamma$-IFN-treated HUVE Strains Derived from Single Donors*

\begin{tabular}{llll}
\hline & \multicolumn{2}{l}{ Percent specific "'In release } \\
\cline { 2 - 4 } Kawasaki donor & HUVE-1 & HUVE-2 & HUVE-3 \\
\hline 1 & 47.6 & 65.0 & 62.8 \\
2 & 37.2 & 27.9 & ND \\
3 & ND & 42.2 & 37.0 \\
4 & ND & 19.5 & 38.8 \\
5 & ND & 25.8 & 45.3 \\
\hline
\end{tabular}

* Sera from five different patients with acute KS were tested for complement-dependent cytotoxic effects on single donor passaged HUVE strains derived from three different subjects. Data were calculated from means of triplicate determinations; all SD were $<10 \%$. untreated and $\gamma$-IFN treated HDF derived from four separate donors. As shown in Table VI, four different acute KS sera were able to lyse $\gamma$-IFN-treated HUVE cells but failed to cause any lysis of either untreated or $\gamma$-IFN-treated HDF. In these same experiments, mouse MAb, LB3.1, directed against HLA-DR, was equally effective in lysing $\gamma$-IFN treated HDF as $\gamma$-IFNtreated HUVE cells.

To exclude the possibility that the results with KS sera might be due to allotypic differences between unrelated donors of HUVE cells and HDF, we examined the effects of acute KS sera on HUVE cells and HDF derived from the same donor. The data in Table VII continued to demonstrate a cytotoxic effect by acute KS sera on $\gamma$-IFN-treated HUVE cells but not on untreated or $\gamma$-IFN-treated HDF derived from the same donor. Convalescent serum from the same KS patients failed to lyse untreated or $\gamma$-IFN-treated HUVE and HDF.

Antibodies in acute KS lyse $\gamma$-IFN-treated HSVE Cells but not $\gamma$-IFN-treated HSVSM. We further examined whether the cytotoxic anti-endothelial cell antibodies in acute KS were directed to endothelial cells derived from HSVE vs. smooth muscle cells derived from the same segment of saphenous vein (HSVSM). As shown in Table VIII, five different acute KS sera lysed $\gamma$-IFN-treated HSVE but not untreated HSVE, untreated HSVSM, or $\gamma$-IFN-treated HSVSM. Furthermore, convalescent KS sera failed to lyse untreated or $\gamma$-IFN-treated HSVE or HSVSM.

Failure of anti-endothelial cell antibody to recognize other cell types. To further determine the cell specificity of anti-endothelial cell antibodies in acute $\mathrm{KS}$, we also tested the capacity of acute KS to lyse $\gamma$-IFN-treated HUVE after adsorption with human erythrocytes, $T$ lymphocytes, B lymphocyte-adherent monocytes, untreated HUVE, or $\gamma$-IFN-treated HUVE. As

Table VI. Acute Kawasaki Sera Lyse $\gamma$-IFN-treated HUVE Cells but not $\gamma$-IFN-treated Skin Fibroblasts*

\begin{tabular}{|c|c|c|c|c|}
\hline \multirow[b]{2}{*}{ Experiment No. } & \multirow[b]{2}{*}{ Cells } & \multirow[b]{2}{*}{ Acute KS donor } & \multicolumn{2}{|c|}{ Percent specific release } \\
\hline & & & $(-) \gamma-$ IFN & $(+) \gamma$-IFN \\
\hline \multirow[t]{9}{*}{1} & HUVE-1 & 1 & 0 & 32.7 \\
\hline & & 2 & 0 & 33.1 \\
\hline & & 3 & 0 & 32.1 \\
\hline & HDF-1 & 1 & 0 & 0 \\
\hline & & 2 & 0 & 0 \\
\hline & & 3 & 0 & 0 \\
\hline & HDF-2 & 1 & 0 & 0 \\
\hline & & 2 & 0 & 0 \\
\hline & & 3 & 0 & 0 \\
\hline \multirow[t]{6}{*}{2} & HUVE-2 & 1 & 0 & 37.0 \\
\hline & & 4 & 0 & 37.4 \\
\hline & HDF-3 & 1 & 0 & 1.2 \\
\hline & & 4 & 0 & 0 \\
\hline & $\mathrm{HDF}-4$ & 1 & 0 & 0 \\
\hline & & 4 & 0 & 0 \\
\hline
\end{tabular}

* Sera from three different patients with acute KS were tested for complement-dependent cytotoxic effects on passaged HUVE and HDF strains. Data were calculated from means of triplicate determinations; all SD were $<10 \%$. In both experiments, MAb LB3.1 (reactive with HLA-DR) caused comparable lysis of HUVE and HDF cells treated with $\gamma$-IFN but not untreated cells. 
Table VII. Acute KS Sera Lyse $\gamma$-IFN-treated HUVE Cells but not $\gamma$-IFN-treated HDF Derived from the Same Donor*

\begin{tabular}{|c|c|c|c|c|}
\hline \multirow[b]{2}{*}{$\begin{array}{l}\text { Target } \\
\text { cells }\end{array}$} & \multirow[b]{2}{*}{$\begin{array}{l}\text { KS sera } \\
\text { donor }\end{array}$} & \multirow[b]{2}{*}{ Phase of KS } & \multicolumn{2}{|c|}{ Percent specific release } \\
\hline & & & $(-) \gamma$-IFN & $(+) \gamma$-IFN \\
\hline HUVE-5 & 1 & Acute & 1.5 & 47.6 \\
\hline HUVE-5 & 2 & Acute & 1.3 & 37.2 \\
\hline HDF-5 & 1 & Acute & 0.5 & 0.2 \\
\hline HDF-5 & 2 & Acute & 0.4 & 0 \\
\hline HUVE-5 & 1 & Convalescent & 1.5 & 2.3 \\
\hline HUVE-5 & 2 & Convalescent & 1.1 & 2.7 \\
\hline HDF-5 & 1 & Convalescent & 0.9 & 0.4 \\
\hline HDF-5 & 2 & Convalescent & 0.4 & 0.1 \\
\hline
\end{tabular}

* Acute and convalescent sera from two different patients were tested for complement-dependent cytotoxic effects on passaged HUVE cells and HDF derived from the same donor. Data were calculated as the means of triplicate determinations; all SD, $<10 \%$. In this experiment, percent specific release with MAb LB3.1 (reactive with HLA-DR) for untreated HUVE cells was $1.3 \%$ and $\gamma$-IFN treated HUVE cells was 67.7\%; and for untreated HDF was $0.4 \%$, and $\gamma$-IFN treated HDF was $53.1 \%$.

shown in Fig. 2, $\gamma$-IFN-treated HUVE effectively adsorbed out cytotoxic anti-endothelial cell activity. None of the other cell types, however, caused significant adsorption of the antibody activity against $\boldsymbol{\gamma}$-IFN-treated HUVE.

Table VIII. Acute KS Sera Lyse $\gamma$-IFN-treated Endothelial Cells (EC) but not $\gamma$-IFN-treated Smooth Muscle (SM) Cells from Saphenous Vein (SV) of the Same Donor*

\begin{tabular}{|c|c|c|c|c|}
\hline \multirow[b]{2}{*}{ Target cells } & \multirow{2}{*}{$\begin{array}{l}\text { KS sera } \\
\text { donor }\end{array}$} & \multirow[b]{2}{*}{ Phase of KS } & \multicolumn{2}{|c|}{ Percent "'indium release } \\
\hline & & & $(-) \gamma$-IFN & $(+) \gamma$-IFN \\
\hline \multirow[t]{8}{*}{ HSVE-1 } & 1 & Acute & 0 & 59.4 \\
\hline & 2 & Acute & 1.0 & 34.9 \\
\hline & 3 & Acute & 0 & 58.5 \\
\hline & 4 & Acute & 0 & 35.2 \\
\hline & 5 & Acute & 1.1 & 41.1 \\
\hline & 1 & Convalescent & 0.5 & 0 \\
\hline & 2 & Convalescent & 0.5 & 0 \\
\hline & 3 & Convalescent & 0.5 & 0 \\
\hline \multirow[t]{8}{*}{ HSVSM-1 } & 1 & Acute & 0.1 & 0 \\
\hline & 2 & Acute & 0 & $\mathbf{0}$ \\
\hline & 3 & Acute & 0 & 0 \\
\hline & 4 & Acute & 0 & 0 \\
\hline & 5 & Acute & 1.0 & 0 \\
\hline & 1 & Convalescent & 0 & 1.5 \\
\hline & 2 & Convalescent & 4.6 & 5.4 \\
\hline & 3 & Convalescent & 3.4 & 0.7 \\
\hline
\end{tabular}

* Acute and convalescent sera from KS patients were tested for complement-dependent cytotoxic effects on passaged HSVE and HSVSM derived from the same donor. In this experiment, percent specific release with MAb LB3.1 for untreated SV-EC and SV-SM was 11.9 and $4.7 \%$, respectively; and for $\gamma$-IFN treated SV-EC and SV-SM was 100 and $84.1 \%$, respectively.

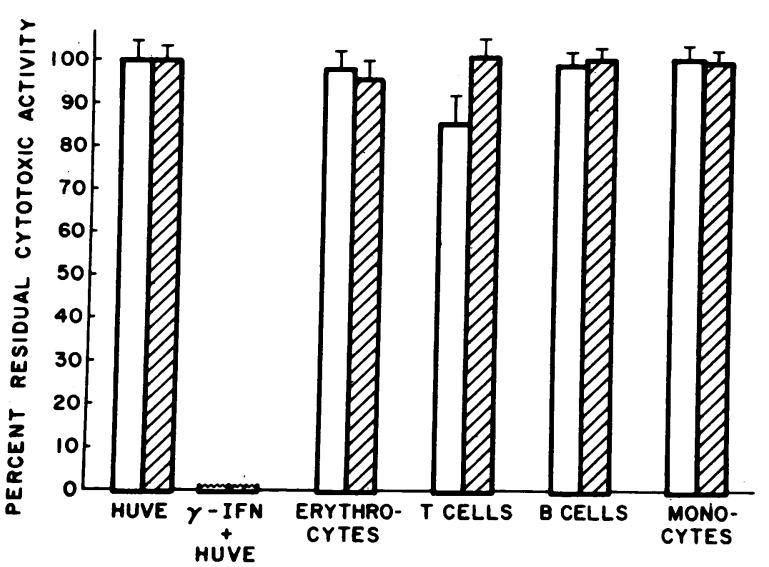

Figure 2. Cytotoxic anti-endothelial cell activity in acute KS sera after adsorption with other cell types. Sera from two acute KS patients were preincubated with packed erythrocytes, $T$ cells, B cells, monocytes, HUVE, and $\gamma$-IFN-treated HUVE, and the residual cytotoxic antibody activity against $\boldsymbol{\gamma}$-IFN-treated HUVE was determined. $\square, \mathrm{KS}$ sera-1; $a$, KS sera-2. Sera adsorbed with untreated HUVE several as a control for $100 \%$ activity. The mean \pm 1 SD of cytotoxic activity in triplicate cultures is shown.

\section{Discussion}

The acute phase of KS is characterized by a diffuse vasculitic process associated with marked activation of the $T$ cell and $B$ cell systems. This study was undertaken to test the hypothesis that vascular damage in acute $\mathrm{KS}$ was initiated by circulating antibodies directed to vascular endothelium. Sera from patients with acute $\mathrm{KS}$ were tested for complement-dependent cytotoxic effects on HUVE cells cultured in the presence or absence of $\gamma$ IFN, a lymphokine secreted by activated T cells. Our current investigation shows that sera from patients with acute KS lyse $\gamma$-IFN-treated cultured HUVE cells but do not lyse untreated HUVE cells (Fig. 1). This cytotoxic anti-endothelial cell activity was complement-dependent because fresh rabbit complement but not heat-inactivated rabbit complement was required to obtain significant levels of ${ }^{111}$ In release (Table II). Preincubation of HUVE with other mediators such as $\alpha$-IFN, $\beta$-IFN, or IL-2 failed to render HUVE susceptible to lysis with sera from acute KS.

No correlation was observed between serum anti-endothelial cell activity in acute KS with the clinical development of coronary artery aneurysms. However, this activity was no longer detectable during the convalescent phase of KS nor was it detectable in normal age-matched controls. The lack of correlation between cytotoxic anti-endothelial cell activity with the development of coronary artery aneurysms is not surprising for several reasons. First, the vasculitis in acute KS is not limited to coronary arteries but also involves other medium-sized arteries and veins, as well as small-sized blood vessels (3-8). In addition, underlying anatomic abnormalities, genetic factors, or differences in the degree of local immune activation may predispose to the development of coronary artery aneurysms.

The cytotoxic anti-endothelial cell activity in the sera of patients with acute KS seemed to be exclusively of the IgM immunoglobulin isotype (Table IV). However, since IgM antibodies are much more efficient at complement-mediated cytolysis than IgG, our studies cannot completely exclude the possibility of 
low level binding to HUVE cells by IgG antibodies in acute KS sera. Several lines of evidence effectively excluded the possibility that the observed cytotoxic effects of acute $\mathrm{KS}$ were being mediated via immune complexes (I.C.): (a) sera from 10 of 10 patients with acute KS used in this study failed to show detectable levels of I.C. by the Raji cell assay or Clq binding assay (data not shown); (b) sera from acute KS subjected to centrifugation at $100,000 \mathrm{~g}$ maintained the same level of anti-endothelial cell activity (Táble III); and (c) the formation of I.C. in normal sera after heat treatment was not associated with an increase in serummediated anti-endothelial cell cytotoxicity (Table III).

Our failure to observe cytolysis of cultured HUVE cells with I.C. and complement would seem to conflict with a previous report (29) that IgG-I.C. could bind to HUVE cultures, leading to monolayer disruption and platelet adhesion. However, in contrast to our studies, the previous report exclusively used primary and first passage HUVE cultures that could contain contaminating peripheral blood monocytes, a cell type known to bind I.C. Indeed, these authors (29) reported that $15 \%$ of the cells in one such HUVE culture stained with monocyte reactive mouse MAb OKM1. We have not seen staining of our HUVE cells with either OKM1 or TS1/18 (directed to the heavy and light chains, respectively, of the complement receptor 3 surface structure) with or without $\gamma$-IFN pretreatment (ref. 27; and J. S. Pober, unpublished observations). Therefore, the biological effects noted above (29) could have resulted from I.C. binding to monocytes and producing a "second messenger" (e.g., arachidonate metabolites). Alternatively, I.C. may bind to HUVE cells without causing ${ }^{111}$ In release, the assay used in our experiments. In any event, I.C. do not account for the results reported in the present study.

The presence of anti-endothelial cell antibodies is not restricted to patients with acute KS. Anti-endothelial cell antibodies have been observed in several other diseases characterized by vascular damage. In particular, patients with acute systemic lupus erythematosis (SLE) have circulating IgG anti-endothelial cell antibodies that initiate complement activation and the adherence of platelets to the endothelial cell surface (29). In contrast, the IgG anti-endothelial cell activity is no longer detectable in sera from these SLE patients after they attain clinical remission. Antibodies to endothelial cells have also been recently implicated in the development of experimental and clinical renal allograft rejection (30-34). The observations made in our present study, however, are unique in that patients with acute KS contain IgM anti-endothelial antibodies against $\gamma$-IFN treated HUVE but not untreated HUVE cells.

The target antigen(s) on the endothelial cell surface recognized by sera from acute $\mathrm{KS}$ is currently unknown. It appears to be a $\gamma$-IFN-inducible monomorphic determinant(s) on HUVE cells. Indeed, all cultures of pooled primary HUVE cells as well as several single-donor-derived passaged HUVE strains were susceptible to lysis by acute KS sera. Gamma interferon increases the surface expression of HLA-A,B antigens and induces the surface expression of HLA-DR (as well as HLA-DP and HLADQ) antigens on HUVE cells and HDF (22). Since anti-Ia antibodies have been reported in the sera of normal subjects after in vivo antigenic stimulation (35) as well as in patients with diffuse vasculitis such as acute SLE (36), it was important to determine whether sera from patients with acute $\mathrm{KS}$ reacted with HLA-DR antigens. Acute KS sera failed to lyse $\gamma$-IFNtreated HDF (Table VI), despite the fact that these cells express Ia antigens $(16,22)$. This was not due to allotypic differences present in unrelated donors of HUVE cells and HDF because sera from patients with acute KS were able to lyse HUVE cells but not HDF derived from the same donor (Table VII). Similarly, we also observed that acute KS sera lysed $\dot{\gamma}$-IFN-treated HSVE but not $\gamma$-IFN-treated HSVSM. Gamma interferon induces the same level of surface HLA-A,B and HLA-DR MHC antigen expression on HDF, HUVE, HSVE, and HSVSM and in these experiments all cell types were lysed with equal efficiency by murine monoclonal antibodies reactive with HLA-A,B and HLA-DR antigens. Furthermore, adsorption of acute KS sera with B cells, monocytes, $T$ cell, or erythrocytes failed to remove the cytotoxic anti-endothelial cell activity. Therefore, our results strongly suggest that the cytotoxic anti-endothelial cell antibodies in acute $\mathrm{KS}$ are not directed to MHC determinants but rather to non-MHC surface antigens inducible by $\gamma$-IFN treatment on vascular endothelial cells but not on dermal fibroblasts or vascular smooth muscle cells. Further studies will be necessary to prove this point.

Vascular endothelial cells are thought to play an important role in maintaining the structural integrity of blood vessel walls. Damage to vascular endothelial cells caused by antibodies may, thus, represent an important mechanism in the pathogenesis of diseases characterized by vasculitis. To our knowledge this report represents the first demonstration of a vasculitis associated with the presence of IgM antibodies directed to $\gamma$-IFN-inducible antigens on human vascular endothelial cells. Since most vasculitides are characterized by marked immune activation and the secretion of lymphokines, further studies are warranted to investigate whether the production of antibodies directed to $\gamma$ IFN-inducible endothelial cell antigens is a widespread mechanism for vascular damage.

\section{Acknowledgments}

The authors wish to thank Dr. Michael A. Gimbrone for providing primary HUVE cell cultures and for his valuable discussions during the course of this research, Dr. Walter Fiers for the gift of human recombinant $\beta$-IFN and $\gamma$-IFN, Dr. Peter Libby for providing saphenous vein endothelial cells and smooth muscle cells, and Paul Cohill and Kay Case for technical assistance in cell culture and Melissa Smith for her assistance in the preparation of this manuscript. We are particularly grateful to Drs. Jane Burns, Jane Newburger, Richard Meade, and Stafford Grady for providing sera from patients with Kawasaki syndrome and control subjects for these studies.

This work was supported by U. S. Public Health Service grants AM31925-01, AI-20373-01, HL27642, and HL22602; and the National Foundation, March of Dimes. Dr. Leung received New Investigator Research Award 5R23HL30082-02. Dr. Geha received Allergic Diseases Academic Award K07 AI0440-01. Dr. Pober was a Searle's Scholar and is now an Established Investigator of the American Heart Association.

\section{References}

1. Kawasaki, T. 1967. Acute febrile mucocutaneous syndrome with lymphoid involvement with specific desquamation of the fingers and toes in children: clinical observations of 50 cases. Jpn. J. Allergol. 16: 178-222.

2. Yanagihara, R., and J. K. Todd. 1980. Acute febrile mucocutaneous lymph node syndrome. Am. J. Dis. Child. 134:603-614.

3. Kato, H., S. Koike, M. Yamamoto, Y. Ito, and E. Yano. 1975. Coronary aneurysms in infants and young children with acute febrile mucocutaneous lymph node syndrome. J. Pediatr. 86:892-898.

4. Kawasaki, T. 1971. Acute febrile mucocutaneous lymph node syndrome and sudden death. Acta. Paediatr. Jpn. (Overseas Ed.). 75: 433-434. 
5. Hirose, S., and Y. Hamashima. 1978. Morphological observations on the vasculitis in the mucocutaneous lymph node syndrome. Eur. $J$. Pediatr. 129:17-27.

6. Landing, B. H., and E. J. Larson. 1977. Are infantile periarteritis nodosa and fatal mucocutaneous lymph node syndrome the same? Pediatrics. 59:651-662.

7. Tanaka, N., K. Sckimoto, and S. Naoe. 1976. Kawasaki disease: relationship with infantile periarteritis nodosa. Arch. Pathol. Lab. Med. 100:81-86

8. Fujiwara, H., and Y. Hamashima. 1978. Pathology of the heart in Kawasaki's disease. Pediatrics. 61:100-107.

9. Morens, D. M., L. J. Anderson, and E. S. Hurwitz. 1980. National surveillance of Kawasaki disease. Pediatrics. 65:21-25.

10. Kato, S., M. Kimura, K. Tsuji, S. Kusakava, T. Asai, T. Juji, and T. Kawasaki. 1978. HLA antigens in Kawasaki disease. Pediatrics. 61:252-255.

11. Krensky, A. M., W. Berenberg, K. Shanley, and E. J. Yunis. 1981. HLA antigens in mucocutaneous lymph node syndrome in New England. Pediatrics. 67:741-745.

12. Leung, D. Y. M., R. L. Siegel, S. Grady, A. Krensky, R. Meade, E. L. Reinherz, and R. S. Geha. 1982. Immunoregulatory abnormalities in mucocutaneous lymph node syndrome. Clin. Immunol. Immunopathol. 23:100-112.

13. Leung, D. Y. M., E. T. Chu, N. Wood, S. Grady, R. Meade, and R. S. Geha. 1983. Immunoregulatory T cell abnormalities in mucocutaneous lymph node syndrome. J. Immunol. 130:2002-2004.

14. Mason, W. H., S. C. Jordan, R. Sakai, M. Takahashi, and B. Berstein. 1985. Circulating immune complexes in Kawasaki syndrome. Ped. Inf. Dis. 4:48-51.

15. Fossard, C., and R. Thompson. 1977. Mucocutaneous lymph node syndrome (Kawasaki disease): probable soluble-complex disorder. Br. Med. J. 1:883-886.

16. Pober, J. S., T. Collins, M. A. Gimbrone, Jr., R. S. Cotran, J. D. Gitlin, W. Fiers, C. Clayberger, A. M. Krensky, S. J. Burakoff, and C. S. Reiss. 1983. Lymphocytes recognize human vascular endothelial and dermal fibroblast Ia antigens induced by recombinant immune interferon. Nature (Lond.). 305:726-729.

17. Weil, J., C. J. Epstein, L. B. Epstein, J. J. Sedmak, J. L. Sabran, and S. E. Grossberg. 1983. A unique set of polypeptides is induced by $\gamma$-interferon in addition to those induced in common with $\alpha$ - and $\beta$ interferons. Nature (Lond.). 301:437-439.

18. Luster, A. D., J. C. Unkeless, and J. V. Ravetch. 1985. $\gamma$-interferon transcriptionally regulates an early-response gene containing homology to platelet proteins. Nature (Lond.). 315:672-676.

19. Gimbrone, M. A., Jr. 1976. Culture of vascular endothelium. Prog. Hemostasis Thromb. 3:1-28.

20. Thornton, S. C., S. N. Mueller, and E. M. Levine. 1983. Human endothelial cells: use of heparin in cloning and long term serial cultivation. Science (Wash. DC). 222:623-625.

21. Jaffe, E., L. W. Hoyer, and R. L. Nachman. 1973. Synthesis of antihemophiliac factor antigen by cultured human endothelial cells. $J$. Clin. Invest. 62:2757-2764.

22. Collins, T., A. J. Korman, C. T. Wake, J. M. Boss, D. J. Kappes, W. Fiers, K. A. Ault, M. A. Gimbrone, Jr., J. L. Strominger, and J. S. Pober. 1984. Immune interferon activates multiple class II major histocompatibility complex genes and the associated invariant chain gene in human endothelial cells and dermal fibroblasts. Proc. Natl. Acad. Sci. USA. 81:4917-4921.

23. Leung, D. Y. M., R. Parkman, J. Feller, N. Wood, and R. S. Geha. 1982. Cell-mediated cytotoxicity against skin fibroblasts in atopic dermatitis. J. Immunol. 128:1736-1741.

24. Scahill, S. J., R. Devos, J. Van der Heyden, and W. Fiers. 1983. Expression and characterization of the product of a human immune interferon cDNA gene in Chinese hamster ovary cells. Proc. Natl. Acad. Sci. 80:4654.

25. Gillis, S., M. M. Ferm, W. Ou, and K. A. Smith. 1978. T cell growth factor: parameters of production and a quantitative microassay for activity. J. Immunol. 120:2027-2032.

26. Barnstable, C. J., W. F. Bodmer, G. Brown, G. Galfre, C. Milstein, A. F. Williams, and A. Ziegler. 1978. Production of monoclonal antibodies to group A erythrocytes, HLA and other human cell surface antigens-new tools for genetic analysis. Cell. 14:9.

27. Muchmore, A. V., M. Megson, J. M. Decker, P. Knudsen, D. L. Mann, and S. Broder. 1983. Inhibitory activity of antibodies to human Ia-like determinants: comparison of intact and pepsin-digested antibodies. J. Immunol. 131:725.

28. Collins, T., A. M. Krensky, C. Clayberger, W. Fiers, M. A. Gimbrone, Jr., S. J. Burakoff, and J. S. Pober. 1984. Human cytolytic T lymphocyte interactions with vascular endothelium and fibroblasts: role of effector and target cell molecules. J. Immunol. 134:1-7.

29. Cines, D. B., A. P. Lyss, M. Reeher, M. Bina, and R. J. DeHoratius. 1984. Presence of complement fixing anti-endothelial cell antibodies in systemic lupus erythematosus. J. Clin. Invest. 73:611-625.

30. Moreas, J. R., and P. Stastny. 1977. A new antigen system expressed in human endothelial cells. J. Clin. Invest. 66:449-454.

31. Cerilli, J., and L. Brasile. 1980. Endothelial cell alloantigens. Transplant. Proc. 12(Suppl. 1):37-42.

32. Paul, L. C., and C. B. Carpenter. 1980. Antibodies against renal endothelial alloantigens. Transplant. Proc. 12(Suppl. 1):43-48.

33. Paul, L. C., L. A. van Es, and W. M. Baldwinn III. 1981. Antigens in human renal allografts. Clin. Immunol. Immunopathol. 19:206-223.

34. Scott, H., P. Brandtzaeg, H. Hirschberg, B. G. Solheim, and E. Thorsby. 1981. Vascular and renal distribution of HLA-DR-like antigens. Tissue Antigens. 18:195-202.

35. Okudaira, K., J. S. Goodwin, and R. C. Williams, Jr. 1982. AntiIa antibody in the sera of normal subjects after in vivo antigenic stimulation. J. Exp. Med. 156:255-267.

36. Okudaira, K., R. P. Searles, J. L. Ceuppens, J. S. Goodwin, and R. C. Williams, Jr. 1982. Anti-la reactivity in sera from patients with systemic lupus erythematosus. J. Clin. Invest. 69:17-24. 